\title{
Technopoiesis as Complex Dynamic Knowledge Construction. A Biopoetic explanation of the Creative Convolution of Human, Natural, and Technological Sciences ${ }^{1}$
}

\section{Tecnopoiesis como construcción dinámica de conocimiento complejo. Una explicación biopoética de la circunvolución creativa de las Ciencias Humanas, Naturales y Tecnológicas}

Juani Guerra

Associate Professor of Department of Modern Languages (ULPGC) Director Interuniversity PhD Program on Cognitive Studies (IUIBS)

Svend 0stergaard

Associate Professor (School of Communication and Culture)

Director Master Cognitive Semiotics (Center for Semiotics)

Reception date: 28 November 2016

Review date: 14 December 2016

To cite this article: Guerra, J. and Ostergaard, S. (2017): Technopoiesis as Complex Dynamic Knowledge Construction. A Biopoetic explanation of the Creative Convolution of Human, Natural, and Technological Sciences, Icono 14, volumen 15 (1), pp. 235-255. doi: 10.7195/ri14.v15i1.1034 


\section{Abstract}

In this paper, we describe technopoiesis as the complex dynamics between four levels of an all-encompassing knowledge configuration. The first level corresponds to the interaction with the environment, mediated by representations and material forms. The second level involves the representations, for instance representations of force, which determine the interaction with the environment. The third level involves the use of material forms in the interaction, for instance using a stick to get hold of a piece of fruit. The fourth level is the technological level as such. From a view of Biopoetics that primarily understands technopoiesis as a synergic and dissipative process based on emergence and feedback conditions, our main contribution in this study consists in a dynamicist description of how these four levels interact with each other. Higher levels emerge from the lower ones, in a complex but deterministic process, where lower levels are also constrained by the higher ones.

Key Words: Technopoiesis - Biopoetics - Diagrammatics - Complexity - Creativity Knowledge - Fiction

\section{Resumen}

En este artículo describimos technopoiesis como dinámica compleja entre cuatro niveles de configuración de conocimiento integral. El primer nivel corresponde a la interacción con el entorno, y está mediado por representaciones y formas materiales. El segundo nivel es el de las representaciones, por ejemplo las de fuerzas, que son las que determinan la interacción con el entorno. El tercer nivel implica el uso de formas materiales en la interacción, como la utilización de un palo para coger una pieza de fruta. El cuarto es el nivel tecnológico como tal. Desde un enfoque Biopoético que entiende tecnopoiesis esencialmente como proceso sinérgico y disipativo basado en condiciones de emergencia y retroalimentación, nuestra principal aportación en este estudio consiste en describir de forma dinamicista cómo los cuatro niveles interaccionan entre ellos siguiendo pautas de complejidad de dichos procesos a lo largo de trayectorias creativas en las que niveles superiores emergen desde niveles inferiores de modo complejo pero determinista, y en el que los superiores limitan a los inferiores.

Palabras clave: Tecnopoiesis - Biopoética - Diagramática - Complejidad - Creatividad - Conocimiento - Ficción 


\section{Introduction}

Human interaction with the environment is mediated by representations, which can in some cases be instantiated in material form (i.e. technology). This paper focuses on those cases where representations can be externalized in the form of signs or sign systems. Peirce classified signs in indexes, icons and symbols, but he further subdivided icons in images, metaphors and diagrams (Peirce, vol2, paragraph 243). Here we consider diagrams and diagrammatic thinking as key elements in the process of poiesis leading to the emergence of technology. One of the reasons is that the diagram as an external representation can be subject to experimentations and manipulations. Moreover, in many cases this is a collective process, based on an interactional dynamics where complex evolution from a simple representation to the final outcome is a synergic and dissipative dynamic process. An extensive discussion of diagrammatic thinking appears in Stjernfelt (2007). We see this stage of diagrammatic thinking as a necessary level between the exigencies of the situation and the material support that can help solving these exigencies. It is also possible to make experimentations on the material level in a feedback interaction with the "diagrammatic" level. The outcome of this experimentation is what we define as "fourth level" where a conventionalized practice in relation to a technology occurs that is entrenched in the culture.

In the framework of Biopoetics, Poetics stresses that these dynamics are part of a general poiesis that integrates technology and Bio- stresses that these processes are inherently biological and sociocognitive. The first level is the genuine biopoetic level where biological agents interact with the environment mediated by mental representations. The second level requires the development of a sign system where the mental representations are externalized in diagrams. The advantage is an offload of working memory and, as stated above, in the case of diagrams it is possible to perform experimentation on them in order to find better representations.

In the framework of Technopoiesis the two first levels focus on poiesis, and the two last levels are specific for the techno part. The third level constitutes the emerging material implementation of the diagrammatic representation. The diagram being a fiction, the third level determines whether this fiction is impossible 
or possible. Finally the fourth level is where the technology is conventionalized both in the form of a name and in the form of practice. We can conclude that at the third level the material form is still in the experimentation state while at the forth level it is implemented as part of cultural knowledge.

\section{Methodology. A Dynamicist Approach to Complex Knowledge Systems}

\subsection{Technopoiesis in the Context of New Paradigms and the Evolution of Disciplines}

One of the core issues about the creative nature of different disciplinary sites within the same culture concerns the complex organization of their harmonization in the construction of a new paradigm. Rather than a linear emergence centered on applications and outputs of a particular discipline, these different sites interact in a non-linear way which might end up in a contemporary instantiation of the same episteme, the same vision of the world. In this scenario, a realistic way to explain how different disciplines are invisibly drawn to similar problems needs to be coherently refocused into a dynamicist framework.

An early attempt to describe the "similarity" between the disciplines appears in Foucault's Les mots et les choses (1966). However, this similarity is neither thematic nor accessible by looking at the surface forms of the different discourses. In an analysis of economics, theory of languages, and the theory of natural forms, in the period 1600-1800, Foucault discovers that underlying the different discourses are some implicit assumptions that guide the research in all cases despite the thematic differences. This implicit schema, which directs the researchers without their knowledge, is what he calls an épistémè. However, the episteme is not related to the interaction or the thinking of the researchers, it is not based on the activities of the researchers, but it is a transcendental structure. We would like to advocate for a dynamics' approach to the description of the merging or splitting of the sciences, so that any convergence of the sciences would be the result of propagating ideas from one discipline to another. This, like Foucault's episteme, would be the acting of an invisible hand but here the "hand" is grounded in human interaction. 
A more poststructuralist approach focused on Complexity Theories and on the new vision of dynamicism was presented by Katherine Hayles in relation to the sciences of chaos:

[...] it is a mistake to assume that the science of chaos has initiated the attitudes that have made it an object of popular fascination. Rather, it is one site within the culture where the premises characteristic of postmodernism are inscribed. The postmodern context catalyzed the forma-tion of the new science by providing a cultural and technological milieu in which the component parts came together and mutually reinforced each other until they were no longer isolated events but an emergent awareness of the constructive roles that disorder, nonlinearity, and noise play in complex systems. (Hayles, 1991, p.5)

\subsection{Complex Dynamics of Technopoiesis: Biopoetics and Cognitive Semiotics}

In our attempt to draw a dynamicist definition of technopoiesis, we will project this grounding épistémè turning point in the description of Knowledge Systems. That is, we will take into account a more realistic interdisciplinary view of what a Knowledge System is, and which marked a second grounding epistemological turning point at the end of the 20th-c. Still visible today, this complex dynamics involves ontogenetic, phylogenetic and cultural processes (Johnson \& Rohrer 2007). We will here start from the foundational consideration of Knowledge Systems as highly dynamic biocultural structurings (Prigogine \& Stengers 1984; Hayles 1991; Balandier 1988); essentially they were understood as highly creative organized systems, as bio(techno)poetic adaptive systems, increasing their complexity in a constant feedback loop between human non-material reality and material reality. As we will explain below, these emergent structurings are embodied, situated, distributed, synergic and dissipative and are built on the relations between the human brain, the human body and the environment in a constant interchange of matter, energy and culture.

Though in a more dynamic way, Foucault still embraced the classical representationalist view of mind as different from contemporary embodied experience that focuses on a pragmatically-centered understanding of knowledge as in the cognitive 
sciences. This paper claims that this context is more optimal than the traditional semantically-centered structuralist one in that its description of creative complexity in terms of emergence and feedback facilitates a more realistic understanding of the ongoing dynamics of meaning construction, hinted within the conception of technopoiesis.

From this fundamentally dynamicist, experiential view of knowledge systems, we will introduce here some premises from Biopoetics (Guerra 2013, 2016) to better understand the evolutionary interactive dynamics of technologies \& sciences/ disciplines that catalyze in the concept technopoiesis. These will help elucidate the problem of linking sign/representation, technology, and science/knowledge from the core of dynamic complexity: the emergent nature of creative feedback processes. For that matter we need to start assuming experience and the organization of sign/representation and of technology as embodied (Lakoff \& Johnson, 1987), situated (Zlatev, 1997), distributed (Hutchins, 1995), synergic (Bernárdez, 2007), and dissipative (Guerra 1992, 2001), and as existing only in a constant constructive feedback loop between material and non- material entities.

\section{Discussion. Diagrammatic Reasoning, Rep- resentation / Sign, and Technology. Dynamic Con- structions of Technopoiesis}

As an all encompassing proposition, the editors of the present volume have claimed that "despite the fact that methods of research and reasoning among various fields of knowledge are often different and even incompatible, the truth is that all human disciplines have evolved based on a unique basic premise: the way in which technology has gradually modified the nature of sign production, distribution and reception, and thus, the entire system of human thought, representation and culture." (López-Varela "Introduction"; Emphasis added). This quotation specifically refers to inventions such as printing, the telegraph, the telephone, the Internet, the cell phone etc., which have undoubtedly changed the way we communicate and therefore also our cultural organization. However, if we focus on the notion "sign production" we might as well say that sign production has gradually changed technology. By this we mean that any technology is developed from some diagrammatic representations, as mentioned in the 
introduction. In Stjernfelt \& Østergaard (2016) a prototypical diagram is defined as “...a two-dimensional geometric representation of something we may qualify as "relations" which might then be spatial/temporal relations, quantitative relations, interpersonal or other relations". The term diagram goes back to Charles Peirce (Peirce 1976, 316ff) who proposed that all human thinking and especially mathematical thinking proceeded in terms of operations on diagrams. For instance, an equation can be considered a diagram on which certain operations are possible. Therefore reasoning with mathematical models is a form of diagrammatic reasoning (Tylén et al., 2014). Thus, this paper argues that there is a dynamic loop between human scientific, diagrammatic representations and the materiality of technology, which drives what we understand as technopoietic systems in the following way: Local exigencies such as communication, need for defense, etc. cause diagrammatic representations to emerge that might be implemented in a material format, i.e. technology, which cause new exigencies that cause a further development of the diagrammatic representations, see Fig.1. The first part of this process concerns poiesis in a broad biocultural sense; the second concerns the social choice of implementing the mental representations in a material form. Once the form is there it can itself be manipulated and modify the diagrammatic representation and consequently the local exigencies.

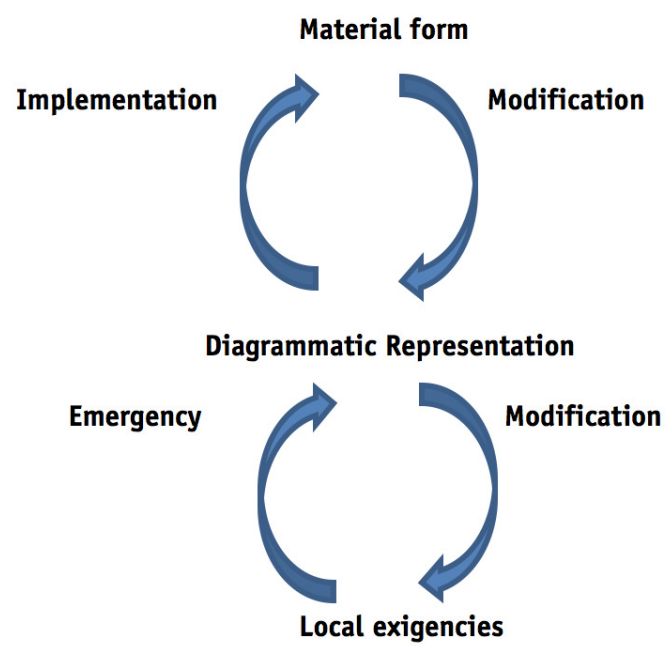

Figura 1 
The editors also propose to understand 'technology' as something that "can be defined as a practical knowledge, engaged in the creation of tools and machines, as well as the development of techniques and methods of organization in order to perform specific functions in making human life easier." In our terms, this could be further improved by technically considering technology as a primary cooperative artifice (an emergent component of knowledge) involved in a synergic dynamics ${ }^{2}$ that solves the human problem of surviving and increasing life style. Essentially, this pragmatic situation is similar to language and other complex adaptive systems in nature.

From a biopoetic approach that explores dynamics of poiesis and autopoiesis (Maturana \& Varela 1978, 1980, and 1987), and given that these experiences and technoconstructions can only be thought of as sociocultural, two important concerns need to be clarified: i) Whether sign systems \& representation forms are needed in order to understand technology as practical knowledge or not; and ii) How are sign and representation altered by technology. Concerning i), if we understand technology as an external material form (an extension of the human body), then as a minimum it requires a representation of force and energy and, in more sophisticated versions it further requires a representation of how energy can be transferred from one domain to another; for instance, from the kinetics of water to the movement of a wheel, or from the combustion of coal to the movement of a piston, etc. It has been claimed that the absence of tool construction in non-human primates is due to the fact that they lack a representation of force. They can sometimes use tools, but it is based on materials that are at hand in the environment and it is mostly based on a trial and error schema and not on any intrinsic understanding of force and energy (Tomasello, 1999).

In relation to (ii) (How sign systems and representation forms are altered by technology), the construction of signs and representations (diagrammatic thinking) is a dynamic process that does not stop because a piece of technology has emerged. We can understand this fact both locally and globally: Locally, a piece of technology is an external representation of a model that in itself gives rise to improvements (cf. the loop in fig.1). Consequently, within a given paradigm improved versions of the same technology can be achieved. Globally, the history of technology is not a linear process; it is a dissipative process with many bifurcations. We define a bifurcation as a point in time where a qualitative new type of representation is used to 
produce a piece of technology that maintains the same function as already existing technology; for instance the invention of the steam engine which took over many functions of the classical watermill. In other words, the production of technological representations (the diagrammatic thinking) goes on independently of the existing technology, but dependent on the level of the representations. For instance, Newton's way of representing force was not motivated by the existing technology but by previous thinking on force representations (Galileo and others).

A piece of technology is then neither a sign nor a representation; this is evidenced by the fact that different types of technology require different types of representations in the process of production. Elementary here is the usage-based way in which we are looking at signs/representations as on-course used in the production process of technology and not as the structural product of technology.

In this scenario we can segment a technopoietic system in some gradational levels: The first three levels correspond to the levels in Fig. 1. The first level is the level of exigencies, i.e. a level of direct interaction with the environment. However, this interaction depends on representations that modify the interaction, reflected in the loop structure in Fig.1. Normally, when we speak of diagrammatic representations we think of external forms that can off-load working memory. However, in an early stage of tool development we can think of internal representations as being sufficient. Such may be the case of the invention of a hammer, which relies on a representation of force dynamic relations, where by force dynamic we refer to any schematic representation of the interaction between two entities, for instance a nail and a hammer (Talmy, 2000). We can find these types of primitive relations even in animals; for instance in the kea (Nestor notabilis), New Zealand mountain parrots that are able to use tools for solving simple problems related to food acquisition. The third level in Fig. 1. is the material level. We can here think of a watermill. It is possible to have a mental representation of the force dynamic relations involved in this technology: transforming the energy of the water flow into the kinetic energy of a wheel that is connected to other wheels doing the work: grinding corn, moving a saw, moving a hammer etc. However, the material support for the technology does in this case require a representation of the design of the construction before it can be realized. 
The development of the watermill can very well illustrate our highlighting of emergency and feedback as crucial in the understanding of technopoiesis: a set of specific exigencies of human interaction with the environment (level 1) is what cause the invention of the watermill (level 3 via level 2), but this changes the conditions to a new level of exigencies which causes improvements of the first watermill creating a new bifurcating trajectory. At this stage we get to the fourth level where we have a category called 'watermill', which is based on a compositional dynamics with many bifurcations into a multitude of watermills. In this view, we can consider 'the watermill' as a generic term for many different instantiations of a piece of technology that in the developed Countries reached an entropic phase and disappeared with the invention of electricity, but it existed together with the steam engine, although in some industries the steam engine substituted the water driven mills. However, in this context it is worth to note that the diagrammatic representations become more and more complex going from watermills to steam engines and to electricity driven machinery. In the end we have technologies like nuclear plants, which require a very complex mathematical representation to be realized.

\subsection{Some Comments on the Four Levels of Emergence and Feedback Dynamics}

1. The level of exigencies never exists on its own. Human interaction with the world is always mediated by representations. If excluding external representations for a moment, human memory system constantly update our experiences and thereby our representations of the situations, which then modify our interaction. What we have here is the basic poietic loop between action and thinking.

2. Our history is a history of externalization of internal representations, for instance, in writing, but also in other forms of sign systems from simple diagrams to mathematical forms. In many cases to get to the right type of technology is dependent on the right type of notation: the invention of the decimal system and Newton's mathematical representation of force were crucial for the technological inventions in the 18th and 19th centuries. Maxwell's representation of electromagnetic waves was crucial for the possibility of sending signals over long distances, etc. 
The sign system might change our representations of the dynamics of the situation. For instance, Newtonian physics change our intuitive cognitive understanding of force dynamic relations, for instance, if I cannot open a window I might say 'the window resisted my pressure' but this indicates a force exerted by the window, which is a wrong way of seeing it according to classical mechanics (Talmy, 2000).

Notice that diagrammatic representations are much more than sophisticated mathematical models, but in all cases it is a kind of sign system where the elements can be subject to experiments in order to find the optimal representation. For instance, in the case of the steam engine you have a system of elements like piston, valve, crankshaft and cylinder, etc. which each play a decisive role in the material realization. This will require a diagram where you might make small experiments on the diagram by ordering the elements in different ways.

3. The material level. The material representation is a piece of technology but at this stage the materiality is subject to experimentations. You can manipulate with the material in order to see how it fits with the diagrammatic representation, or you can manipulate with the diagram to see if it is possible to implement it at the material level. This is why in Fig. 1. we consider a feedback loop between the representation and the materiality.

4. The technological level. This is where the material implementation has become an entrenched part of the culture and thus we have a category, like for instance, 'car'. It is clear that even at this stage you can imagine improvements that can be tried out at the representational as well as the material level. Our technological devises change all the time, and the motivation for this comes in part from the interactional level; for instance, the number of people that have been killed by cars has caused a considerable change in the design and construction of automobiles. From this, it should be clear that there is not only the feedback loops represented in Fig. 1., in fact there are feedback loops between every two of the four levels, as shown in the figure. 


\subsection{Technological Artifices as Emergent Entities}

In the view presented here any technological artifice can be considered as an entity that emerges from the level of sign/diagram production, but observe that the technology itself is not a sign and, consequently, that we have two ontologically different levels that interact. We have considered this emergent structure as a result of a feedback loop between human interaction with nature (this is what we have called exigencies above) and the materiality of technology. This also poses certain problems, causing that once technology is invented it becomes integrated in this former feedback process, thus increasing the complexity of the relation (you interact with nature, then you create a new piece of technology that interacts with nature etc.).

This embodied, situated, distributed, synergic and dissipative dynamics of creative non-equilibrium between tools and machines on one hand and techniques and methods on the other is realistically a source of science/knowledge order, assuming a natural increasing technological complexity on-course as any form of poiesis (Guerra 2011), say diagrammatic reasoning/representation that makes any addition function probable.

Consequently, in each of the above mentioned levels we find a technopoietic situation that could be modeled as a bifurcation diagram, as in Prigogine and Stengers' (1984) dissipative dynamics, which informs us about the limits of stable operations in the dynamic system of knowledge construction which inherently and synergically tends to optimal unification through consilience as in Edward Wilson (1998).

Framed in the evolution of human culture, the fact that there is an increasing, cumulative complexity of technology could be described in terms of Tomasello's "ratchet effect". Tomasello (1999) uses this metaphor to demonstrate that human social learning is qualitatively different from non-human primates and that this is what makes a culture qualitatively different and thus human. In contrast with chimpanzees' culture, human cultures are cumulative on time, simulating a ratchet effect. Thus, once a piece of technology is invented you can never go back to a previous state; after the computer, for instance, no one used the old typing machine any more. The theoretical explanation for this dynamics is centered on the notion of imitation (Tomasello, 1999). 
In this sociocognitive view we can refer to these entities as knowledge technoconstructions; these entities can activate two different meanings depending on their framing on materiality or on non-materiality. On the one hand, tools and machines are seen as given, in such a way that the basic cognitive action of users is to recall that materiality from their knowledge storage system. On the other hand, certain technical elements are seen as "constructed", i.e., as the result of some special, individual poietic/poetic operations; such can be the case of fiction and myth. This state of things reflects the traditional discussion on the nature of the process of building technical elements, especially in the robotics: whether robotic constructions are built every time they are used, on the base of rules, or whether they are simply recalled from some kind of robotic storage system.

Furthermore, synergic fiction (technoconstruction) develops the notion of distributed fiction (myths) in conditions where a group of individuals cooperate to solve the problem of carrying out a complex technological activity with a lower individual poietic effort. Moreover, synergic technoconstruction adds a historical component, in such a way that the results of cooperative activities at a certain point of time are internalized by individuals (myth), who are then able to recall the way of carrying out individually a specific activity. A historically cooperative activity then is carried out by an individual on a later moment that increases the probabilities of transforming the technological device itself and the myth in a coherent continuum of creative complexity driven forward by emergence and feedback forces. It is in this way that we understand technoconstructions as dissipative structurings. (Prigogine \& Stengers 1984; Guerra 1992).

\section{Results. Fiction, Poiesis and Technopoiesis}

As knowledge system, this cumulative evolution of technology based on emergences and feedback predominantly concerns poetics and specifically how culture/ technology can be modified/created by culture/technology. The dynamicism of this highly interactive process is robustly pushed forward by a living complex Poetics that is the focus of Biopoetics (Guerra 2013, 2016; Silvera \& Guerra 2016; Martínez \& Guerra 2016; Morales \& Guerra 2015; Góral \& Guerra 2016). From this viewpoint if we think of this process as (i) a compositional one (more Poetic) and 
not so much as (ii) a descriptive one (more Hermeneutic), this facilitates a more coherent understanding of poiesis as configuring technology and of technology as configuring poiesis in the Golden Braid compound of technopoiesis.

I. The compositional perspective can be better understood from the perspective of a Biopoetics that focus on how the interaction between biocultural human operations and technological mechanisms make sign production probable, improbable or impossible. In this dynamicist frame we can consider a piece of technology as an emergent entity able to modify the entire system of human thought, representation and culture. In this view technology is open, as stated above, for new restructurings and changes, and the creative variables would be infinite depending on the environments.

II. The descriptive perspective springs from the interpretation of what the piece of technology does, and from here, to understand praxis as effects of technology (Structuralism) from which human beings develop methods. On the contrary poiesis encompasses emergent dynamic épistémè (Poststructuralism and after).

Our view is that the process of developing representations of knowledge that makes it possible to create technology is not different from other processes where structure emerges from interaction between people. For instance, when economy and trading became so complicated that it was necessary to keep track of the flow of goods and money a notation system was invented; this was the case of the Babylonian cuneiform script. However the notation system caused the economic flow to become even more complicated so that a refinement of such system was necessary. In line with Robinson (2003) we view this feedback loop between economic praxis and the development of a notational system as the motor in the development of a new technology: the writing system. As we will see below we call poiesis the process that leads to a bifurcation in the representational formats used by humans; whether these representations can be used to construct material artifacts (technology) or they can be used to construct new forms of social interactions (for instance, trading or communications) we consider the process at a poietic level for the same. This biopoetic view follows from the general theory of complex adaptive systems (see for instance Miller \& Page, 2007). 
In the compound techno-poiesis the semantic category poiesis is thus located at a superordinate level in the terminology from Rosch (1978), whereas the category techno in the sense of material realization of the poietic process exists at a lower level together with languagepoiesis, culturepoiesis etc. In this sense, the process (knowledge) that creates technology is not different from the process that creates language or any other cognitive structure.

\subsection{The Diagrammatic Representation as Fiction}

We will now survey the external representational level in the model above, i.e. the level where the representation is presented in an external format. The creation of this external format constitutes a bifurcation point. We have defined poiesis as the process which causes this bifurcation to emerge; this is essentially the loop between level 1 and 2 in Fig.1. This process is in all cases mental, but it can be a collective process where a number of humanists, artists, scientists etc. interact in creating the mental model. The result of the process in all cases at this stage of the evolution is what we usually understand as a fiction. A diagram over a steam engine is a fiction as long as it is not implemented in a material format. We can here evoke different possibilities, which also constitute bifurcation points: The model can be impossible, and in that case it remains a fiction. It can also be possible, and if so, there are two possibilities: its implementation in a material format can be probable or improbable. This bifurcation involves a social choice, should the model be materialized or not. In the first case it goes into the dynamics of evolving the technology in question.

The poietic bifurcation can give rise to at least three qualitative different types of fiction:

1. A diagram for a possible construction that is never materialized. This is the simplest form and the history of science/technology shows many examples. Most famous are Leonardo da Vinci's non-realized diagrams for different -possible but improbable-technical devices. The reasons for the non-materialization of the models can be many, but they are mostly either economic or based on the assumed functionality of the model. In cases where it cannot be ruled out that the functionality is impossible it is still possible to construct

DOI: ri14.v15i1.1034 | ISSN: 1697-8293 | Año 2017 Volumen 15 Nº 1 | ICONO14 


\section{MONOGRÁFICO}

the model. We use the term impossible mainly for models that cannot even be constructed. As an example we can mention "The Devil's Triangle": we can make a model of this triangle but only in $2 \mathrm{D}$; in $3 \mathrm{D}$ it is impossible.

2. The second type of fiction is a theoretical construction, where the theory involves fictional elements that are necessary for the construction of the material implementation. In poiesis, and therefore in the theoretical model, there are elements that remain fictional, even if there is a physical materialization of the model. It is not difficult to give examples: Maxwell's electromagnetic waves are fictional elements (in the sense that we do not know the physical reality of these waves) which makes it possible to construct devises that can transfer information over long distances. Cardano's use of the square root of a negative number is another example of a fictitious element (a so-called imaginary number), which is necessary to perform the non-fictive process of solving an equation of degree 3; even semantically, the very concept of root that grounds the mathematical meaning of square root is fiction in itself, initially projecting a botanic similarity to metaphorically think of the side of a square as the root of a plant (Lizcano 2016). Any notational construction that makes operations possible can be considered as a fiction, even the decimal system which we do not usually consider as fictional because of its deep cognitive entrenchment.

3. The third example of fictional constructions is what we term as "fiction". However, there is a deviation from the previous cases because what is deemed 'fiction' is not the diagrammatic representation of the object, as in the case of Leonardo da Vinci, but it is the already constructed object that is fiction: That cannot be made. A case in question can be the Terminator, a machine made of floating metal that can take on any form and simulate any voice etc. This is impossible, but we readily accept these constructions because they fit into a temporal and historical schema: what is not possible today could be possible tomorrow; we have also examples from science fiction where the characters travel in space from one solar system to another. We know this is impossible, but it could be that new aspects of space/time will be discovered (like wormholes, which as it stands today is a theoretical fiction) so that this travel becomes possible. From impossible to possible there is an entrenched schema that underlies all fictive constructions, be they scientific or literary. 


\section{Conclusions}

A definition of the semantic category technopoiesis has been approached from principles of dynamic systems and biopoetic and cognitive semiotic theory. Crucial concepts in this interdisciplinary theoretical frame have been explored in relation to technopoiesis; among them the following:

Synergy, which refers to a dynamic interaction between a set of components where each component is locally constrained by the others while at the same time contributing to the global result. In the poietic context this is what happens when many agents contribute to the evolution of science and technology. The constraining part of such a dynamics might explain the "unification of knowledge" if such one exists.

Emergence, which refers to the result of many agents interacting, with no single agent being responsible for it. This is contrary to the standard view of science where any single invention theoretical or technical is connected to a single inventor. However, this is a fiction. With the possible exception of Einstein, any single inventor is dependent on hundreds of other agents working in the same field, as Newton formulated it: "I am standing on the shoulders of giants".

Feedback, which refers to the fact that the emergent global structure constrains the dynamics at the local level. In that sense it is similar to synergy. For instance, the emergent technology constrains the kind of interaction you can have with the environment and also the kind of poiesis that will ensue.

Biopoetics. This is a general disciplinary frame for the dynamics referred to by the previous three concepts. Poetics stresses that these dynamics are part of a general poiesis that integrates technology and bio stresses that these interactive processes are inherently biological and sociocognitive.

Our main claim in this study is to underline that the biopoetic process organizing technopoiesis involves at least four levels, with emergences and constrains between the levels. Furthermore, we see technopoiesis as the dynamics between 
these four levels based on mechanisms expressing the relation between biology, poetics and external representations that cognitively and socio-culturally ground the evolution of technology.

\section{Notes}

[1] This research was partially supported by the FLinT Center for Fundamental Living Technology (Syddansk University, Denmark) where the first author shared for 6 months (2012) a life of wisdom and creativity with colleagues who provided insight and expertise that greatly assisted the core of these ideas. Special thanks to its Director, Steen Rasmussen, for his realistic integration of the Humanities in the heart of Science and Technology. We also aknowledge the support by the Canarian Research Council ACIISI (Agencia Canaria de Investigación, Innovación y Sociedad de la Información) Project Reference: SolSub C200801000234e.

[2] The dynamics we are considering here is synergetic in the sense that a multitude of elements are interacting and mutually constraining each other. The system is thus both determined by freedom and constrainment. For instance an inventor can come up with a new idea (freedom) but it is still constrained by already existing technology and knowledge in the field.

\section{References}

Balandier, G. (1988). El desorden. La teoría del caos y las ciencias sociales. Elogio de la fecundidad del movimiento. Barcelona: Gedisa 1990.

Bernárdez, E. (2007). Synergy in the construction of meaning, in Fabiszak, M. (ed.) Language and Meaning, pp. 15-37. Frankfurt/Main: Peter Lang.

Foucault, M. (1966). Les mots et les choses. Paris: Gallimard

Johnson, M. and T. Rohrer (2007). We Are Live Creatures: Embodiment, American Pragmatism, and the Cognitive Organism. In Zlatev, J., Ziemke, T., Frank, R. and Dirven, R. (Eds.) Body, Language, and Mind, vol. 1, 17-54.. Berlin: Mouton de Gruyter, Gamoneda, A. (2015). Resistencia y flexibilidad de la analogía. Modelos científicos, cognición y metáfora. En Gamoneda, A. (Ed.), Espectro de la analogía. Literatura y Ciencia. Madrid: Abada Editores.

Góral, M., Guerra, J. (2016). Cognición, Lengua y Dinámicas Biopoéticas de Evolución Social en Ortega y Gasset. Modelos Cognitivos de Organización Temporal del Concepto Humano en el Texto La Deshumanización Del Arte (1925). Tesis Doctoral ULPGC: Acceda.

Guerra de la Torre, J.T. (1992). La naturaleza creativa del tiempo en el nuevo paradigma del Caos: Una relectura de T. S. Eliot. Madrid: S.P.U.C.M. 
Guerra, J. (2001). Simplixity and Complexity. The Topology of the Short Story and the Novel. Short Story Journal. 9, 1, Texas: CELJ.

Guerra, J. (2010). What Cognitive Sciences as an interdisciplinary framework can contribute to the study of Literature in general and of Edgar Allan Poe's literary texts in particular, en Estévez Fuertes, N., Llácer Llorca, E. V. y Olivares Pardo, M. A. (Eds.) Genius and psicosis in Edgar Allan Poe. New interdisciplinary perspectives. Valencia: Servei de Publicacions de la Universitat de València.

Guerra, J. (2011). Cognitive Poetics and Biocultural (Con)figuration of Life, Cognition and Language. Towards a theory of socially integrated science Pensamiento. Revista de Investigación e Información Filosófica. 67, 254, 843-850.

Guerra, J. (2013). Poética Cognitiva: (Con)figurándonos lo real, en Hermosilla, A. y Calero, M.L. (Eds.) Lenguaje, Literatura y Cognición (pp.253-271). Córdoba: S.P.U.C. Guerra, J. (2016). Nueva Poética para una transversalidad realista. Revista de Occidente. Metáfora y Ciencia. Madrid: Fundación Ortega y Gasset. 422-423, 32-44.

Hayles, K. (1991). Chaos and Order. Complex Dynamics in Literature and Science. Chicago: The University of Chicago Press.

Hutchins, E. (1995). Cognition in the Wild. Cambridge, MA: MIT Press.

Johnson, M. (1987). The Body in the Mind: the Bodily Basis of Meaning, Reason and Imagination. Chicago: University of Chicago Press.

Lakoff, G. (1987). Women, Fire and Dangerous Things: What Categories Reveal About the Mind. Chicago: The University of Chicago Press.

Lizcano, E. (2006). Metáforas que nos piensan: Sobre ciencia, democracia y otras poderosas ficciones. Madrid: Traficantes de Sueños.

Lizcano, E. (2009). Imaginario colectivo y creación matemática. La construcción social del número, el espacio y lo imposible en China y en Grecia. Barcelona: Gedisa Editorial. Lizcano, E. (2016). ¿Extraer la raíz de un cuadrado? Revista de Occidente. Metáfora y Ciencia. Madrid: Fundación Ortega y Gasset. 422-423, 88-104.

Martínez, J.J., Guerra, J. (2016). Dinámicas Biopoéticas del Prototractatus y El Tractatus Logico-Philosophicus de Ludwig Wittgenstein. Arquitectura Cognitiva de las Proposiciones. Tesis Doctoral ULPGC: Acceda.

Maturana, H.R., (1978). Biology of Language: The Epistemology of Reality, in: Miller, G., Lenneberg, E. (Eds.), Psychology and Biology of Language and Thought, pp. 28-62. Academic Press, New York. 


\section{MONOGRÁFICO}

Maturana, H., Varela, F., (1980). Autopoiesis and Cognition: The Realization of the Living. D. Reidel: Boston.

Maturana, H., Varela, F., (1987). The Tree of Knowledge: The Biological Roots of Human Understanding. Shambhala: Boston.

Miller, J.H. \& Page, S.E. (2007). Complex Adaptive System. Princeton: Princeton University Press.

Morales, M. \& Guerra, J. (2015). Biopoética y Lingüística Cognitiva. Proyecciones metafóricas y conceptualización de Zeit en el texto Der Zauberberg de Thomas Mann. Tesis Doctoral ULPGC: Acceda

Peirce, Charles S. (1931-58). Collected papers of Charles Sanders Peirce. 8 volumes. Ed. by Charles Hartshorne, Paul Weiss and Arthur W. Burks. Cambridge, MA: Harvard University Press. [Reference will be designated Peirce followed by volume and paragraph number.]

Peirce, Ch. (1976). New elements of mathematics. Carolyn Eisele (Ed.), I-IV. The Hague: Mouton.

Prigogine, I. \& Stengers, I. (1984). Order out of Chaos: Man's new dialogue with nature. N.Y.: Flamingo.

Robinson, A. (2003). The Origins of Writing, in Crowley, D. and Heyer, P. (Eds), Communication in History: Technology, Culture, Society. (p.36). Allyn and Bacon, Rosch, E. (1977). Human categorization, in Warren, N. (Ed.) Studies in crosscultural psychology 1. London: Academic Press, pp. 1-49.

Rosch, E. ([1978] 1999) Principles of categorization, in Lloyd, B. and Rosch, E. (Eds), Cognition and Categorization, (pp. 27-48). Hillsdale, NJ: Erlbaum; reprinted in E. Margolis and S. Laurence (Eds) (1999) Concepts: Core Readings, (pp. 189-206). Cambridge, MA: MIT Press,

Silvera, M., Guerra, J. (2016). Biopoética, Cognición y Emoción. Integración Conceptual y Emergencia en The Crying of Lot 49 de Thomas Pynchon. Tesis Doctoral ULPGC: Acceda.

Sinha, Chris. (2015). Language and other artifacts: socio-cultural dynamics of niche construction. Front. Psychol. 6: 1601.

Stjernfelt, Frederik (2007). Diagrammatology: An investigation on the borderlines of phenomenology, ontology, and semiotics. Dordrecht: Springer. 
Stjernfelt, F \& Østergaard, S. (2016). Diagrammatic Problem Solving, in Thinking With Diagrams - The Semiotic Basis of Human Cognition. Krämer, S. \& Ljungberg, Ch. (Eds.). (pp. 103 - 119) Berlin: De Gruyter Mouton

Talmy, L. (2000). Force dynamics in language and cognition, in Talmy, L. 2000 Toward a cognitive semantics. Concept structuring systems, vols. 1 \& 2. Cambridge, MA: MIT Press.

Tomasello, M. (1999). The Cultural Origins of Human Cognition. Cambridge, MA: Harvard University Press.

Tomasello, M., Rakoczy, H., (2003). What makes human cognition unique? From individual to shared to collective intentionality. Mind \& Language 18 (2), 121147.

Tylén, K., Fusaroli, R., Bjørndahl, Raczaszek-Leonardi, J., Østergaard, S., Stjernfelt, F. (2014). Diagrammatic reasoning. Abstraction, interaction, and insight. Pragmatics \& Cognition 22:2, 264-283.

Zlatev, J. (1997). Situated Embodiment : Studies in the Emergence of Spatial Meaning. Stockholm : Gotab. 